\title{
A Software Model for Parameters Affecting the Dimensions of Reinforced Concrete Prefabricated Facade Elements
}

\author{
By Mustafa Tosun ${ }^{*} \&$ Enes Yasa
}

\begin{abstract}
In this study, a model software of a computer program related to determining dimensional behavior, which will contribute to the multi-layered units used on the facade of industrial buildings to be standardized, has been prepared. By means of this model software, the factors determining the width (A), the height ( $h$ ) and the section (d) of the units of a building facade, could be evaluated. These factors, at the same time, from the dimensions of building facade units providing "thermal insulation, sound insulation statically behavior and coordination dimension of facade unit." In the program (named as MT2 Prefabrike), these four factors could be evaluated by providing the optimization in sequence and within themselves. Thus, by developing a new method of approach in the standardizing of facade units, apart from the visible characteristics of the units, the idea of standardizing the performance and behavior expected from the units, are put forward. In the model program formed with this idea, before producing of the facade units, the optimization is to be provided by analyzing the factors which are effective in giving dimension to the units, in abstract condition (computerized).
\end{abstract}

Keywords: a model software, building facade unit, prefabrication, thermal and sound insulation, static behavior analysis, the facades of industrial buildings

\section{Introduction}

There are many studies on building modeling. They bring all the stages of construction closer to a predictable system. Building information modeling (BIM) is one of the most promising recent developments in the architecture, engineering, and construction (AEC) industry. With BIM technology, an accurate virtual model of a building is digitally constructed. This model, known as a building information model, can be used for planning, design, construction, and operation of a facility. It helps architects, engineers, and constructors visualize what is to be built in a simulated environment to identify any potential design, construction, or operational issues. BIM represents a new paradigm within AEC - one that encourages integration of the roles of all stakeholders on a project. The architecture, engineering, and construction (AEC) industry has long sought out techniques to decrease project cost, increase productivity and quality, and reduce project delivery time. Building information modeling (BIM) offers the potential to achieve these objectives (Azhar et al. 2008). When completed, the building

\footnotetext{
*Associate Professor, Konya Technical University, Turkey.

${ }^{ \pm}$Associate Professor, Istanbul University, Turkey.
} 
information model contains precise geometry and relevant data needed to support the design, procurement, fabrication, and construction activities required to realize the building (Eastman et al. 2008).

The future of BIM is both exciting and challenging. It is hoped that the increased use of BIM will enhance collaboration and reduce fragmentation in the AEC industry and will eventually lead to improved performance and reduced project costs (Azhar 2011).

This study conducts analyses in order to determine (static) behaviors in terms of thermal, sound and conveying features expected from an element while forming the element cross-section in order to make use of "Coordination Dimensions" in defining the dimensions of reinforced concrete pre-fabricated facade elements which are used in industrial structures' facades (Wang-Dong et al. 2011). A computer software was created in order to conduct these analyses. For this software, Delphi was used. Delphi is a visual software development tool which was developed by Borland. It is Pascal-based and object-oriented (Lantim 1998). In the study, the "MT2 Prefabrike" program was prepared for dimensional analysis.

With the "MT2 Prefabrike" analysis program, analyses can be done on "thermal insulation, sound insulation, sizing and conveying properties (static)" for non-conveying reinforced concrete pre-fabricated and multi-layered facade elements used in Industrial structures' facades. For this purpose in this program, a "Program Flow Diagram" was prepared which indicates the relationship and transitions among data (Figure 1). This developed model works with the system outlined in the flowchart in Figure 1 and reaches the result. The model is definitively completed when all the stages in Figure 1 are concluded in accordance with the calculations.

Figure 1. Flow Diagram for "MT2 Prefabrike" Analysis Program

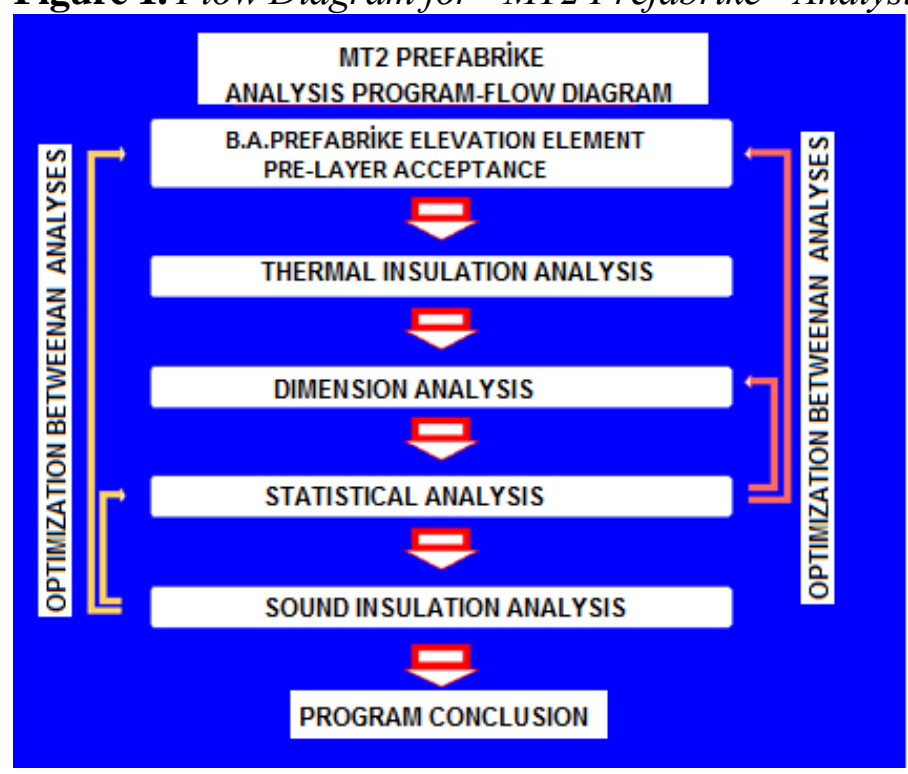




\section{Model Introduction and Application of Model}

The limitations which define the dimensions of reinforced concrete prefabricated industrial structures should be regarded as data intended to standardize the element (Cansun 1989). The element has three dimensions, namely horizontal dimension (width), vertical dimension (height) and cross-section (Christiane et al. 2018).

\section{Factors Which Affect the Cross-Section Size of Facade Elements}

In the "MT2 Prefabrike" program the analyses (thermal insulation, sizing, static and sound insulation) were represented in separate menus and these were optimized in their interactions among each other.

Heat Insulation of Facade Elements

Heat transmission coefficient in construction elements is expressed with the " $U$ " symbol and its value is explained as "W/M ${ }^{2} \mathrm{k}$ ". It is expressed in "watt" units (Joule/sec). It describes air which transitions from a $1 \mathrm{~m}^{2}$ surface to another surface under $10 C^{0}$ temperature (TSE 825 1999, Chudley 1994).

For this reason, "MT2 Prefabrike" was prepared in line with the "thermal insulation requirements for buildings" directive which was published on 18 December 2013. Separating Turkey into five zones in terms of thermal insulation applications (Table 1), the directive prescribes that structures be insulated in accordance with environmental conditions and properties, and indicated of such insulation by drawing up a heat insulation project (TSE 825. 1999).

Table 1. Heat Transmission Coefficients (U) of Facade Element According to Zones (Eriç 1994)

\begin{tabular}{|l|c|c|c|c|}
\hline & $\mathbf{U}_{\mathbf{D}}\left(\mathbf{W} / \mathbf{m}^{2} \mathbf{K}\right)$ & $\mathbf{U}_{\mathbf{T}}\left(\mathbf{W} / \mathbf{m}^{2} \mathbf{K}\right)$ & $\mathbf{U}_{\mathbf{t}}\left(\mathbf{W} / \mathbf{m}^{2} \mathbf{K}\right)$ & $\mathbf{U}_{\mathbf{P}}\left(\mathbf{W} / \mathbf{m}^{2} \mathbf{K}\right)$ \\
\hline Region-I & 0.66 & 0.43 & 0.66 & 1.8 \\
\hline Region-II & 0.57 & 0.38 & 0.57 & 1.8 \\
\hline Region-III & 0.48 & 0.28 & 0.43 & 1.8 \\
\hline Region-IV & 0.38 & 0.23 & 0.38 & 1.8 \\
\hline Region-V & 0.36 & 0.21 & 0.36 & 1.8 \\
\hline
\end{tabular}

Example Solution Using the "MT2 Prefabrike" Software-Forming Facade Element Layers

The starting point for formation of the layers to be used in the whole analysis of the reinforced concrete pre-fabricated element is a selection in the main "thermal analysis" menu in the program. After this selection, an array of windows will be displayed on the screen. In the first window, the number of layers, which form the cross-section of the element, is entered (Figure 2). We can form a layer cross-section example like below, using values for material, thickness and related heat conductivities (Table 2). 
Figure 2. Layer Quantity Window for the Element in the "MT2 Prefabrike" Program

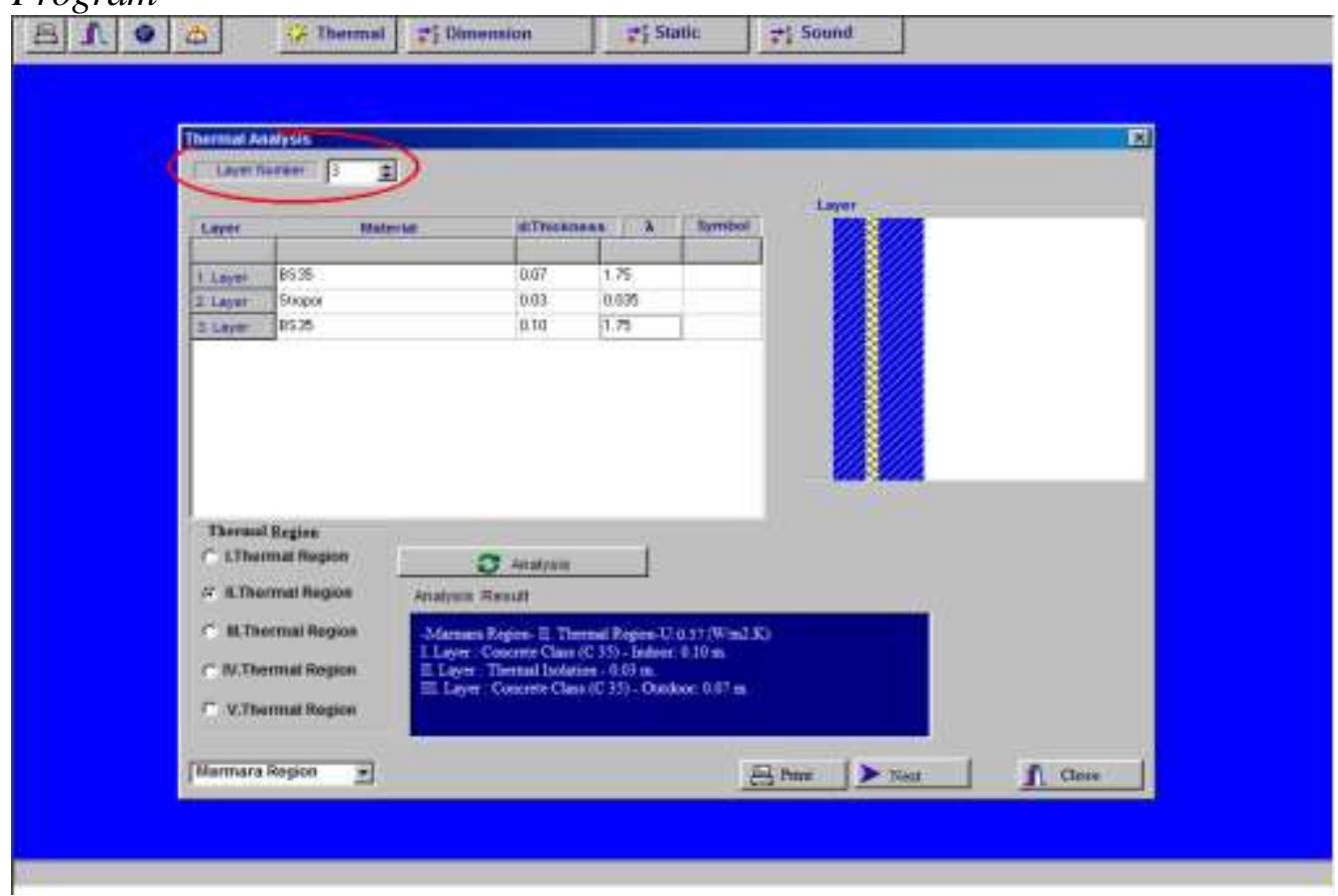

Table 2. Sample Cross-Section Data Used in the Program

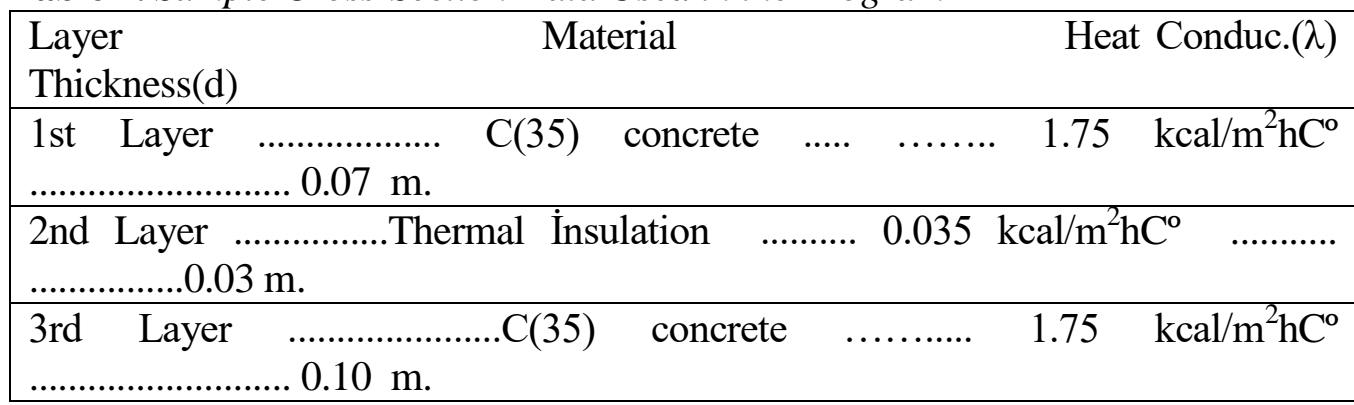

Figure 3. Sample Cross-Section of the Element, to be Analyzed in the "MT2 Prefabrike" Program

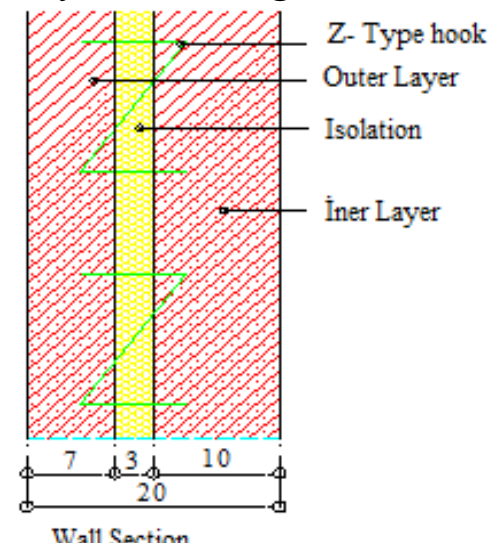


Together with the reinforced concrete pre-fabricated facade element's layers, the "Heat Conductivity Coefficient $(\lambda)$ " will be automatically given in selection of each material from the material window, as seen in Figure 1. Afterwards, material thickness (m.) must be entered. Formation of the facade element's layers will also provide a representation for each material in the symbol window. Therefore the material can be recognized in the analyses; wall section layer has been given in Figure 3.

\section{Thermal Zones}

The program's menus feature a "thermal zone" parameter. In order to determine the thermal zone where the industrial structure is to be constructed, the only action required is to select the name of construction zone from the "Thermal Zone" parameter. The program will take this zone as the base and then show the "Heat Transmission Resistance $(\mathrm{R}=1 / \lambda)$ " $\mathrm{m}^{2} \mathrm{hC} / \mathrm{kcal}$ " value for the zone, of which value can be used in inquiries.

\section{Thermal Analysis}

The analysis on expected thermal behavior from the facade element of reinforced concrete pre-fabricated industrial structures, that is, determining whether the element has suitable insulation according to selected thermal zone, can be conducted via pressing the "Analysis" button (Figure 2). The equation uses the below formula:

$$
\text { Ro }=1 / \lambda=(\mathrm{d} 1 / \lambda)+(\mathrm{d} 2 / \lambda)+(\mathrm{d} 3 / \lambda)
$$

Figure 4. Thermal Insulation Calculation Results in the "MT2 Prefabricated" Program

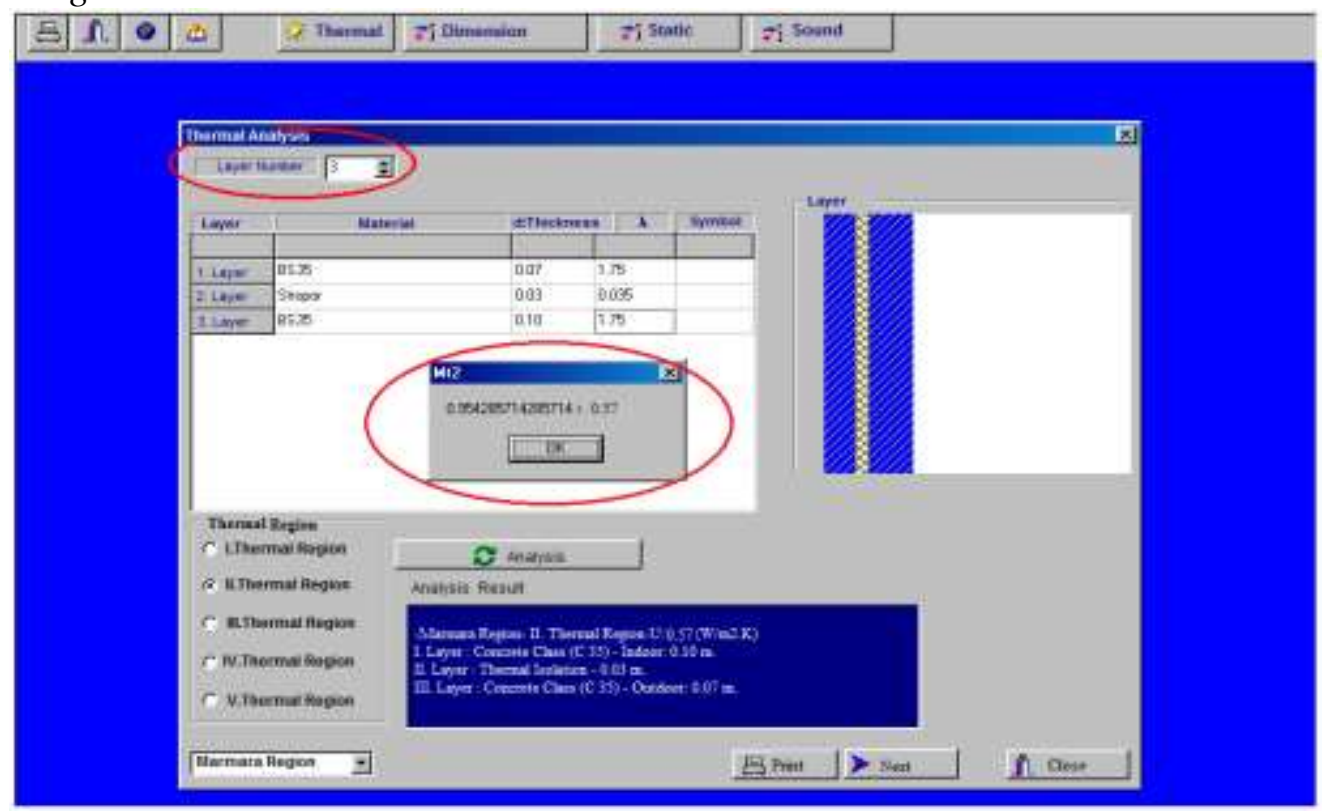


Analysis Results

This section of the program is shown in the menu called "Analysis Results" where all the results are displayed and the print outputs can be obtained. Here are the names of the materials that make up the layer, their thickness, the heat zone and the information that evaluates the suitability of the result. The results of the analysis are shown in Figure 4.

In the MT2 evaluation program, necessary feedbacks can be made by considering a dynamic structure for the case where appropriate values for the building site Heat Zone do not come out. The program has a "print" command window in which the analysis results can be printed. You can then proceed to the sizing analysis with the "Next" command button or you can exit the program with the "Close" command button.

\section{Factors Which Affect the Height of Facade Elements}

In reinforced concrete pre-fabricated industrial structures, the height of facade elements can be varied according to the structure's height and the element's position in the facade. For this reason, factors such as the height of the industrial structure, facade design and transport of the elements affect the outcome.

\section{Factors Which Affect the Width of Facade Elements}

The factors which affect the widths of reinforced concrete prefabricated industrial structures also include the factors that are to be evaluated in the computer program. These are factors such as the opening where the element will be positioned, joint width and joint tolerances, number of elements in the opening and whether to position the elements on the front or behind carriers. In facade element design, one of the most important factors which affect element width is the element's design alternatives. The design of the facade element is also directly related to the design of the building facade. Named "Modular Coordination", the system was derived from the Latin word "Modulus" (small scale) (Figure 5) (Escrig et al. 1996).

Artificial Neural Networks are systems made up of artificial nerve cells that imitate problem solving skills of biological nerve cells by communication and that only living things possess (Montali et al. 2017). These networks discover the connections among attributes inside the samples and can make it possible to classify a sample that they have never encountered before. The discovery process of connections among previous samples is called the training of artificial neural networks. The classification plays an important role for the accuracy of results.

However, when an appropriate solution is found for network classification during the process, it can be possible to focus on this solution. At this point, the artificial neural network algorithm is optimized with the help of the firefly algorithm, which is a powerful and fast optimization algorithm, in order to decrease this sticking possibility (Montali et al. 2017). 
Figure 5. Basic Module $(M=10)$

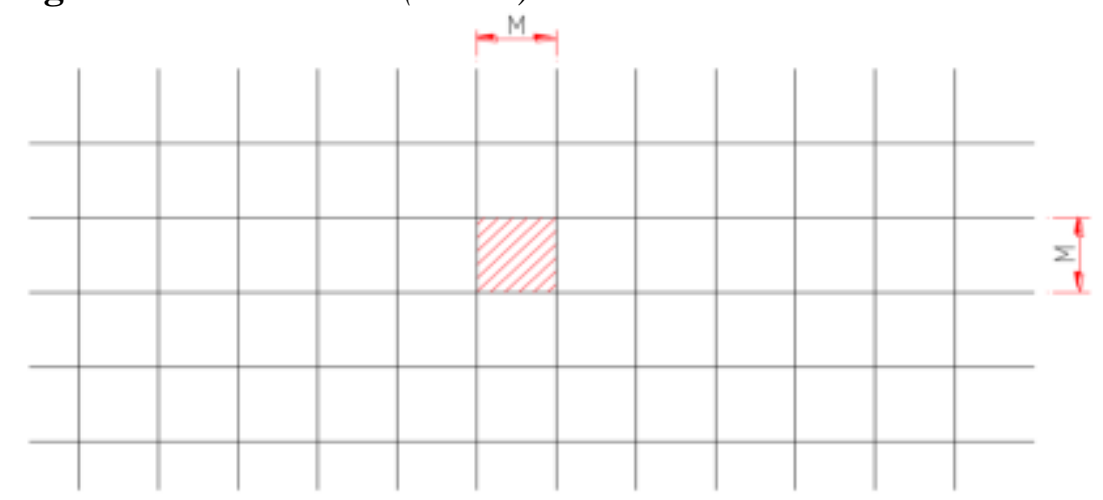

Reinforced concrete pre-fabricated facade elements are placed in (n) quantity into the shaft opening of the carrier system, therefore entering this structure. In the dimensional coordination, shaft opening (D) is obtained with multiple repetitions (n) of the basic module (M); (nxM) (Figure 5). Facade elements which are in relation to another, that is, which enter dimensional coordination, should be within coordination lines and their coordination dimensions should also be equal (Figure 6). It is called the "position line" which determines the location of the facade elements in dimensional coordination. We can express the position of the facade element in dimensional coordination in the following terms:

$$
\begin{aligned}
& \mathrm{D}=\mathrm{n} \times \mathrm{M} \text { Shaft opening }(\mathrm{cm}) \\
& \mathrm{n}=\text { Basic module coefficient (quantity) }
\end{aligned}
$$

$\mathrm{M}=$ Basic Module (cm). Can be M, 2M, 3M, or 1.5M, 0.75M, 0.5M, etc. times of the basic module (Şener 1990).

The reinforced concrete prefabricated facade elements, which are used in industrial structures' facades, fit into the modular coordination and are placed into the shaft opening obtained. In order to make the facade element in a computer environment suitable to the needs of decision-makers, it is necessary to design in the direction of modular coordination principles. Elements are sized using $\mathrm{M}=10$ $\mathrm{cm}$, which is the basic module.

Figure 6. The Position of Prefabricated Facade Element on the Modular Grid

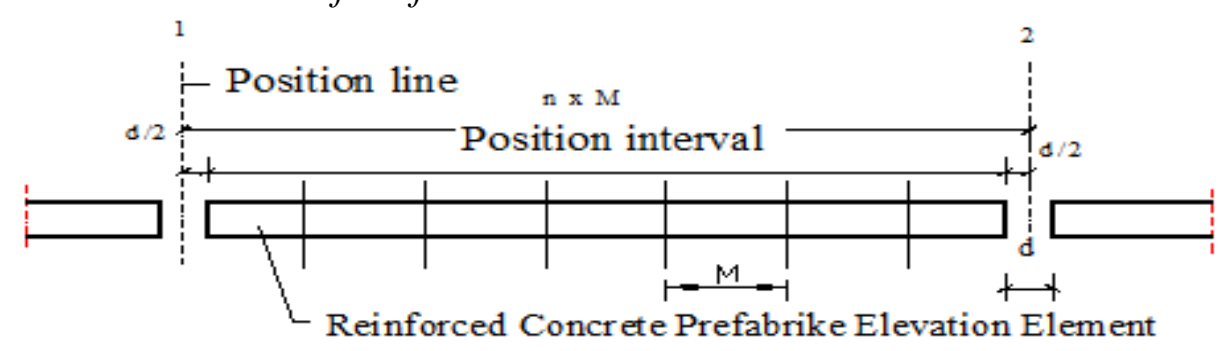

In order to be able to decide how many (n) multi-layered elements to produce and what the mould size, that is the net width (A), would be in reinforced concrete pre-fabricated, the element's position in the facade within the element design has 
to be determined. For this, two design alternatives, which are fundamental to the MT2 Prefabricated Computer program and affect the determination of the widest dimension of the element, are taken into consideration.

Design of Prefabricated Facade Elements Between Columns

If reinforced concrete prefabricated facade elements are designed to be between load-bearing columns (Figures 7 and 8) below equation can be used, depending on the distance between columns, in order to calculate the net width of the element $(\mathrm{A})$ :

$$
A=\frac{\left.\mathrm{D}-\left[\left(\frac{\mathrm{b} 1}{2}\right)+\left(\frac{\mathrm{b} 2}{2}\right)+(\mathrm{n}+1) \mathrm{xd}\right)\right]}{\mathrm{n}}
$$

d=Joint width

$\mathrm{D}=$ Shaft opening measurement of load-bearing columns $(\mathrm{cm})$

$\mathrm{A}=$ Pre-fabricated facade element size

$\mathrm{n}=$ Number of elements

$\mathrm{b}=$ Column size

Figure 7. Designing Prefabricated Facade Elements Between Columns

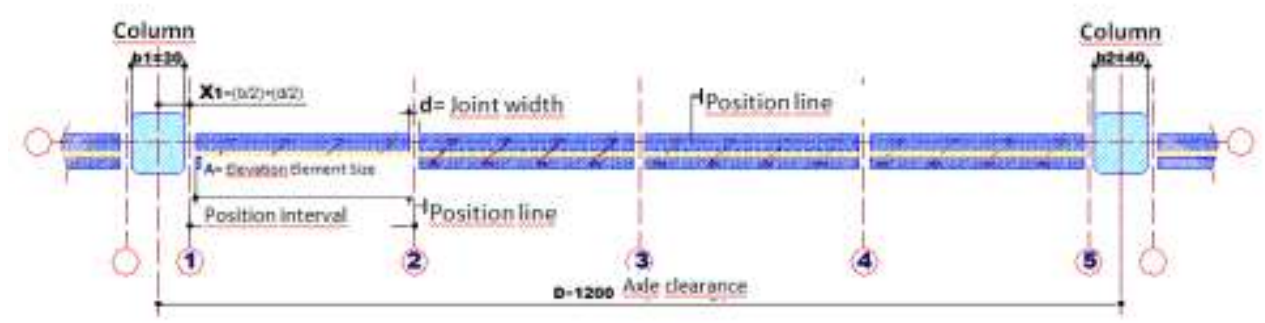

Figure 8. Positioning Prefabricated Concrete Facade Element Between Columns

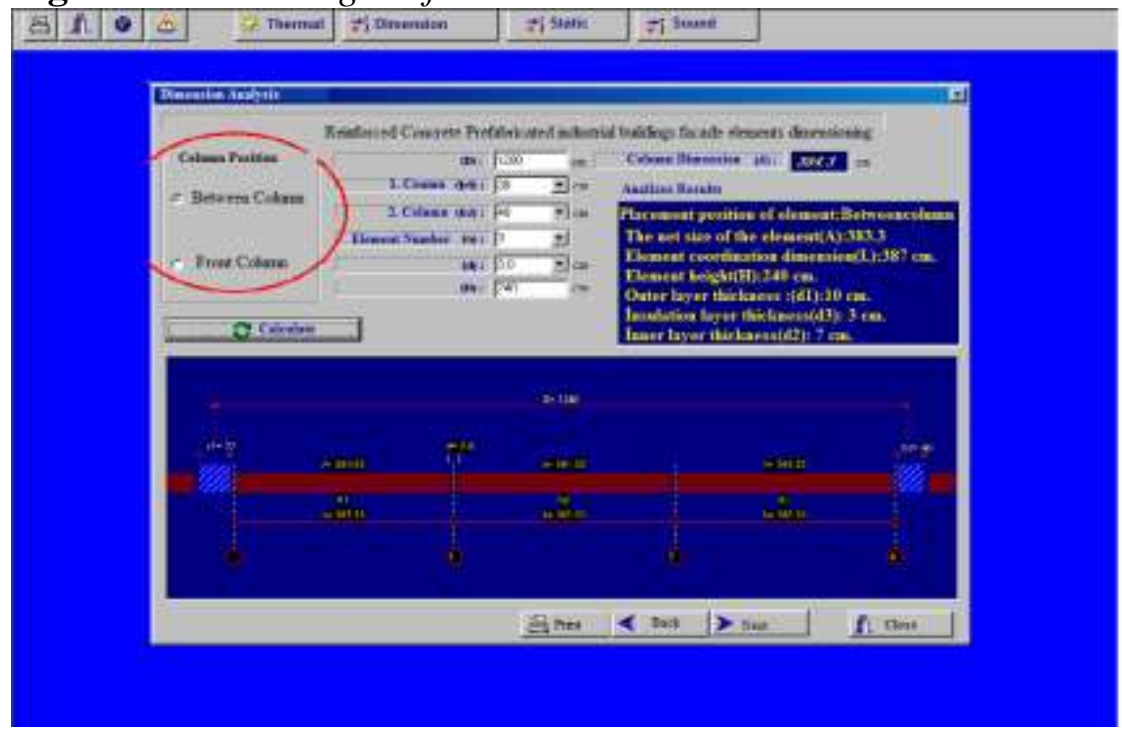

In this program, the net element size (A) can be recalculated by changing the number of facade elements (n). The element size will then be calculated as 
"Facade Element Net Size" A=130.6 in the top right corner of the program. The program contains the "Analysis Results" section which shows all the data of the facade element and the net element size (A) according to this data. The program also has a graphical representation of the facade design of the facade element, with all the values written on the element (Figure 8).

When the process of finding the maximum size (A) of the program element is completed, the "Next" button can be pressed to move to the next step, or the analysis results can be printed out with the "Print" command. In addition, you can return to thermal analysis with the "Back" command for optimization at element size. You can use the "Close" message to exit the program.

Designing Reinforced Concrete Prefabricated Facade Elements on the Front of the Columns

If reinforced concrete pre-fabricated facade elements are designed to be on the front of load-bearing columns (Figure 9), below equation can be used, depending on the distance between columns, in order to calculate the net width of the element (A):

$$
A=\frac{\mathrm{D}-(\mathrm{nxd})}{\mathrm{n}}
$$

d=Joint width

$\mathrm{D}=$ Coordination size (Shaft opening size)

$\mathrm{A}=$ Pre-fabricated facade element size

$\mathrm{n}=$ Number of elements

Figure 9. Designing Reinforced Concrete Prefabricated Facade Elements on the Front of the Columns

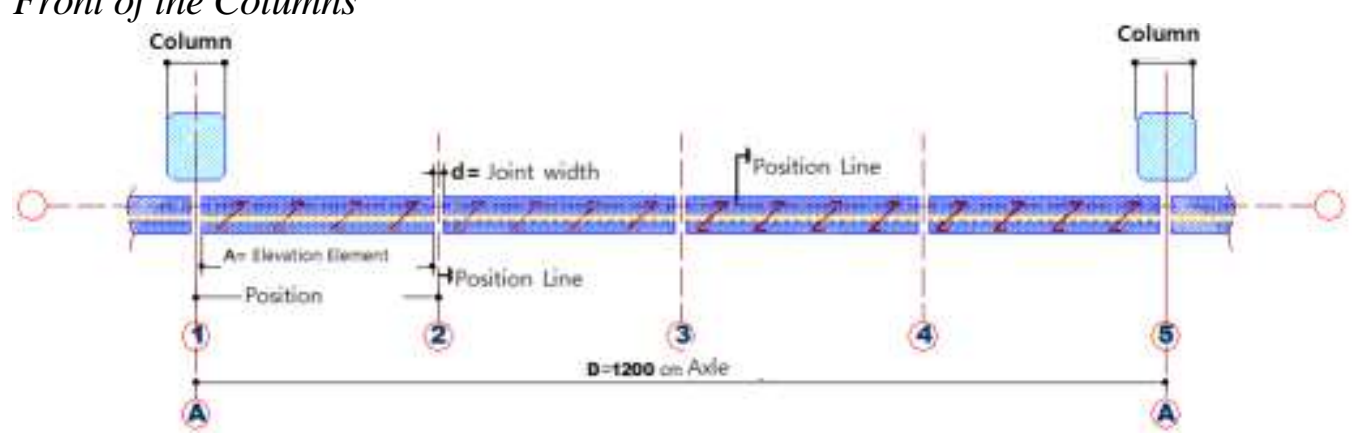

In this part of the program, an assessment can be made to determine the width dimension of the element directly involved in the production, lifting, transport, assembly processes of the front elements used in the reinforced concrete prefabricated industry structures and tool capacities.

In this part of the program, an assessment can be made to determine the width dimension of the element directly involved in the production, lifting, transport, assembly processes of the front elements used in the reinforced concrete prefabricated industry structures and tool capacities. 
Analysis Results

The net element size (A) found at the end of the sizing analysis of reinforced concrete prefabricated multi-layer elements used in the facades of industrial structures will be visually included in the analysis results of the program. The "Analyze" window will show the facade design, the visual results and the results and evaluations of all the calculations. These data are shaft distance, coordination size, column width (b), joint tolerance width and calculated net element size (A) to be obtained from the mould.

\section{Load-Bearing (Static Structure) of Facade Elements}

From the production stage, a facade element needs a cross-section fitting that resists loads such as lifting, transport and wind effects. In order to resist these loads, the carrier inner-layer forming the element, the insulating material between and the outer layer move together.

This connection, which forms the cross section of the facade element, must form a rigid structure against the above static forces. In this section, the inner loadbearing layer of the element will be dealt with, which counteracts the static factors affecting the cross-sectional dimension of the element, the lifting forces, the loads that occur during transport and the wind effects.

\section{Lifting Control}

The position where the reinforced concrete pre-fabricated facade elements, which are used in industrial structures' facades, receive the most deflection risk, occurs at the moment when the element has to be lifted.

Facade elements are lifted from their hooks and a substantial load occurs in at this moment. This load delivers an equal momentum to both ends of the facade element, thanks to a balanced positioning of lifting hooks (Figure 10).

Figure 10. Cross-Section and Lifting Points of Prefabricated Concrete Facade Elements
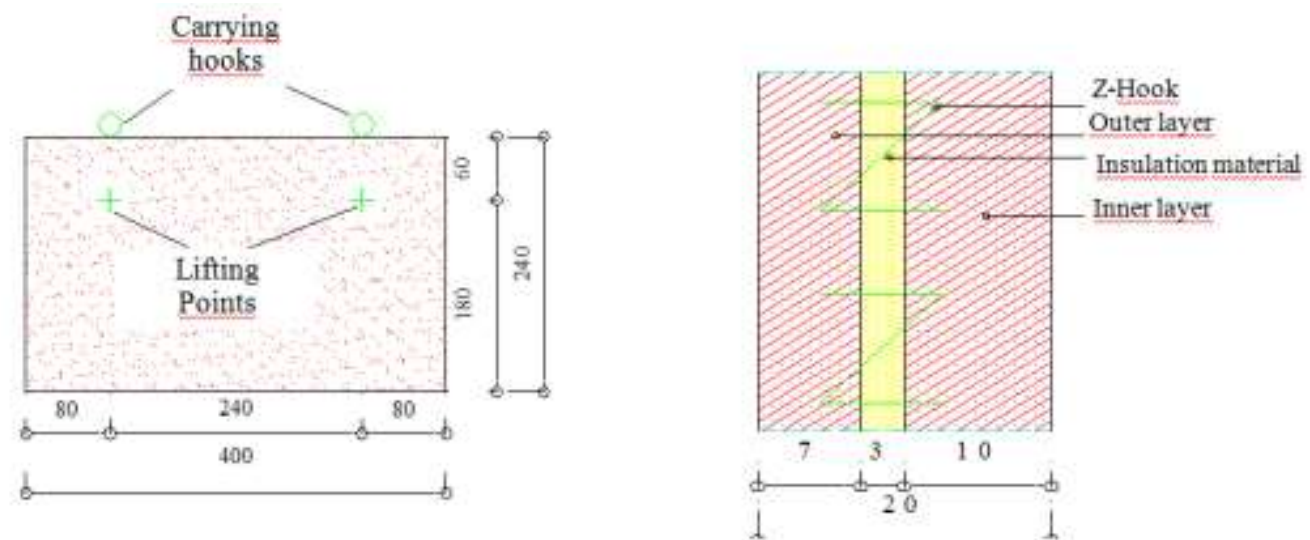

Equations 4, 5 or 6 can be used to calculate the lifting force received by the element (Figure 11).

$\sigma=$ Tensile Stress 
$\sigma=\mathrm{M} / \mathrm{W}\left(\mathrm{Kg} / \mathrm{cm}^{2}\right)$

Where:

$$
F_{\mathrm{ck}}=300 \mathrm{~kg} / \mathrm{cm}^{2} \quad \mathrm{f}_{\mathrm{ct}}=150 \mathrm{~kg} / \mathrm{cm}^{2}
$$

$\mathrm{l}=$ Abutment distance $(\mathrm{cm})$

$$
\begin{aligned}
& -\mathrm{M}=\left(\mathrm{q} \times \mathrm{l}^{2}\right) / 2 \\
& \mathrm{~W}=\left(\mathrm{L} \times \mathrm{D}^{2}\right) / 6
\end{aligned}
$$

$\mathrm{L}=$ Element width $(\mathrm{cm})$

$\mathrm{D}=$ Element cross-section $(\mathrm{cm})$

$\mathrm{q}=$ Spread load $(\mathrm{t} / \mathrm{m})$

Figure 11. Lifting Moments in Prefabricated Concrete Facade Elements

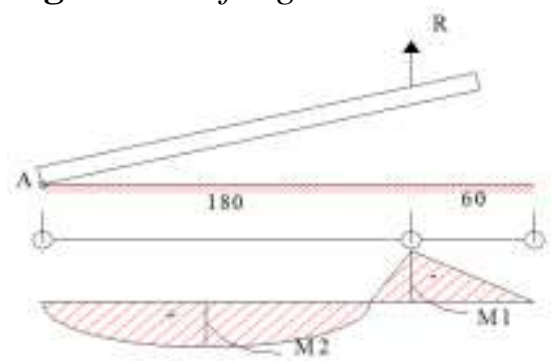

With the tensile stress calculation there will be an analysis of whether or not cracks will occur during lifting. This method can also be used in the computer program and the tensile strength can be calculated using equation 7 :

$$
\left.[\sigma<0.9 \sqrt{ } \text { fci }]<11.02\left(\mathrm{Kg} / \mathrm{cm}^{2}\right)\right]
$$

Where:

$0.9 \sqrt{ }$ fci=Maximum tensile stress for prestressed joint sections

fci=Pressure value on day "I" $\left(\mathrm{kg} / \mathrm{cm}^{2}\right)$

$\mathrm{i}=$ The age of the concrete at the moment of removal from the mold (Bakır 1990).

\section{Bearing Control}

After the production of the reinforced concrete pre-fabricated multi-layer facade elements used on the facades of industrial buildings, static calculations of the hooks must be made in order to be able to meet the loads coming to the transport hooks at the moment of transport to the construction site. This calculation is carried out as below for the " $\mathrm{R}$ " hooks seen in Figure 12 (Bakır 1990). 
Figure 12. Load on Bearing Hooks of Prefabricated Concrete Facade Elements

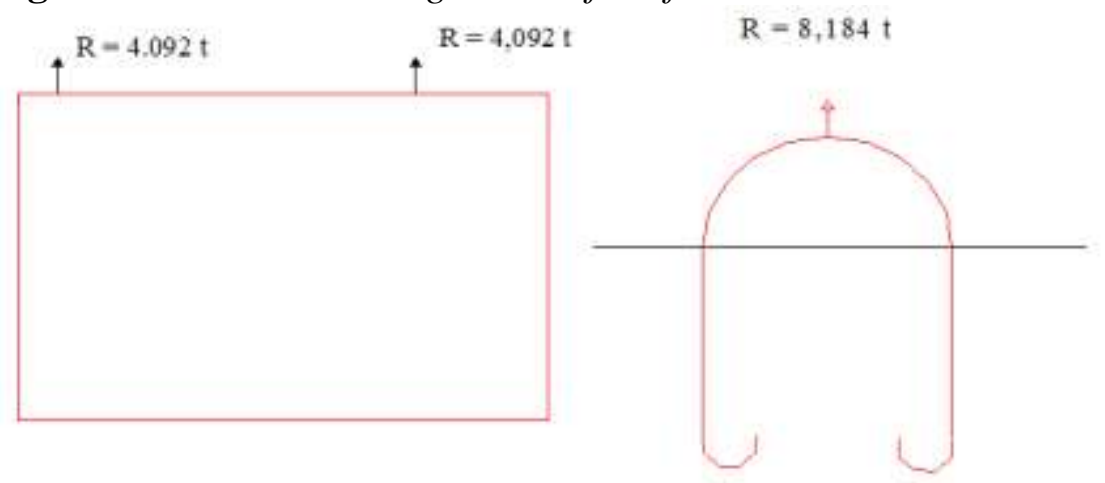

$\mathrm{R}=\mathrm{G} /$ tons

Static load coeff. $=4$

$\mathrm{R}$ total $=4 \mathrm{x} \mathrm{R}$ tons

$\mathrm{R}=$ Load on Bearing Hooks (tons)

$\mathrm{G}=$ Facade element weight (tons)

\section{Wind Control}

One of the problems facade elements can encounter after installation are Wind Impacts. The load resulting from Wind Impacts should be taken into account in the sizing analysis, although it is very small relative to the effect at the time of lifting (Figure 13).

Figure 13. Wind Load on Prefabricated Concrete Facade Elements

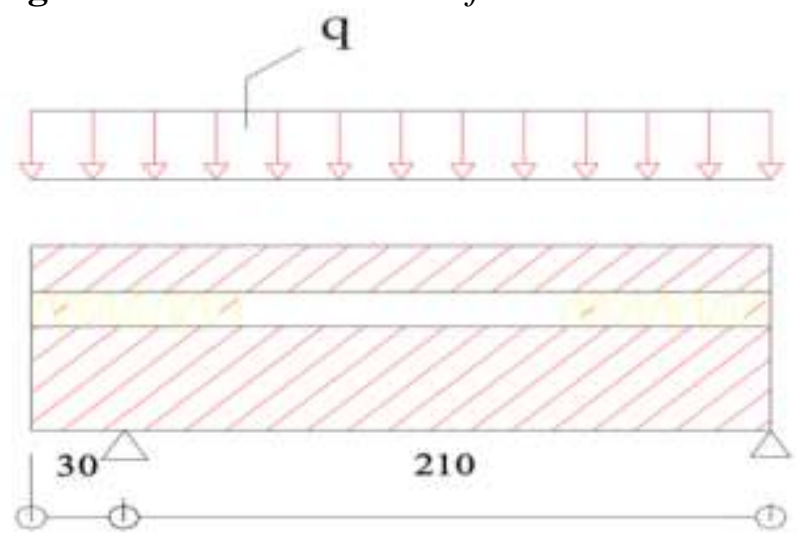

\section{Calculations for the Tie Bars}

In formation of cross-sections for Prefabricated Concrete Facade elements, tie bars are used between the outer layer and the inner layer. When these bars are placed, it is important that the cross-section is sufficient. Also, care must be taken to ensure that where the steel rods are placed have sufficient strength to support the building envelopes during lifting of the element. The highest pulling force on the tie rods will occur when the element is being lifted from the mould.

In "MT2 Prefabrike" static analysis program menu, at the very top, the element's total weight coming from its cross-section will be shown in two 
windows; the building envelope weight (Outer layer + Inner layer), and insulation weight.

Next there will be the window containing fck. and fct. values, which vary according to concrete class (C-35) (Figure 14). These values are decided upon during the "Thermal Analysis" stage by selecting concrete class during formation of building envelope layers. This is because all data of the program work in integration with one another.

\section{Lifting Control Analysis}

An analysis is made on the forces the element gets subjected to while it is lifted from the mould. This analysis is then shown in a window in the program menu. To do this, simply select the "Calculate" command in the lifting control analysis. This is because all data required for Lifting Control Analysis is also used commonly by "Thermal Analysis" and "Sizing Analysis".

Figure 14. Data Connected to Concrete Class Used in Static Analysis

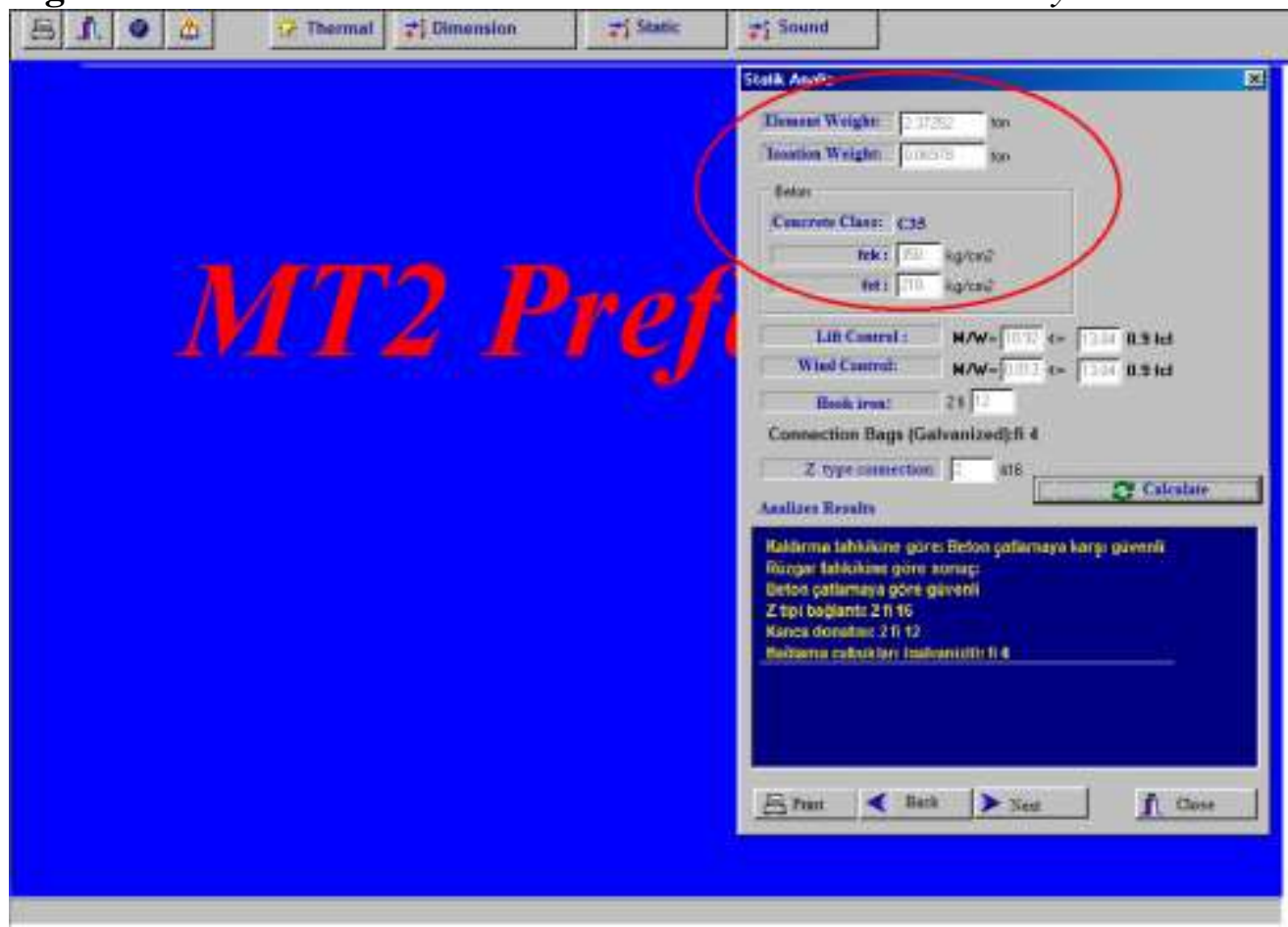

\section{Bearing Control Analysis}

In bearing control analysis, the hook fitting, which is expected to lift the element during the bearing action, will be calculated. The result will then be used to give the user the quantity of hook fitting and fitting diameter in the program menu. The result will be displayed in the "Hook Fitting" window. Since all values are taken from "Temperature and Sizing" analyses, here it will suffice to just use the "Calculate" command button. 
Wind Control Analysis

In order to determine reinforced concrete prefabricated facade elements' behavior against wind loads, calculation results are displayed in the "Wind Control" window. If wind control calculations yield a result that is plausible against given dimensions, the program will not display any error messages. If $\mathrm{M} / \mathrm{W}<0.9 \mathrm{fci}$, this means that a plausible size is selected and there will be no need to revise the size in the program.

Analysing Tie Bars

Diameters and quantity of the tie bars, which provide connection between inner and outer building envelope of reinforced concrete prefabricated facade elements, are displayed in a window in the program.

\section{Analysis Results}

The inquiries made with the "Static Analysis" of reinforced concrete prefabricated multi-layered facade elements used in industrial structures' facades are displayed in the "Analysis Results" window in the program. Here, the evaluation is based on whether any cracks will occur, using lifting and wind analyses. The number and diameter of hook fittings and binding reinforcements are also displayed in the Analysis window. If there is a negative result such as cracking of the concrete in evaluation, changes can be made to the size parameters of the element and the operation can be continued until a positive result is obtained. These parameters are: concrete class and the quantity of hook fittingsif cracking of the facade element cannot be prevented with these parameters, the user should go back to the sizing analysis and make changes in element quantity $(\mathrm{n})$, element height $(\mathrm{h})$ parameters. Then the statistical analysis is complete. Afterwards, pressing the "Next" command button in the right bottom corner for further analyses or the current analysis can be printed out using the "Print" command.

\section{Sound Insulation of Facade Elements}

The term "sound" is used for vibrations in the $16-20,000 \mathrm{~Hz}$ frequency range which the human ear can hear. ISO-acknowledged values are 20-20,000 Hz (ISO 1990). The National Academy of Sciences- National Research Council, Committee on Hearing, Bioacoustic Biomechanics (CHABA) determined sound emitting threshold for soundwave frequency zone as $20-12,000 \mathrm{~Hz}$ (Young 1988).

Sound insulation materials that form a cross-section of the "Reinforced Concrete Prefabricated" multi-layer facade elements provide insulation at different levels. In order to be able to make this decision, optimum decisions have to be given among some criteria. The most important of these is the level of sound proofing desired. If people work within the industry structure, the following levels of continuous, maximum volume will be needed depending on the hours of operation.

$06.00-22.00<60 \mathrm{~dB}$ 
$22.00-06.00 \quad<\quad 50 \mathrm{~dB}$ (Young 1988).

For ease of understanding the effects of sound levels, the sound level $(\mathrm{dB})$ of the sound sources given in Table 2 should be known. Table 3 gives acceptable background sound levels for human activities (Beranek and Ver 1992). In reinforced concrete prefabricated industry structures, the frequency with the largest amplitude, produced by two layers forming the cross-section by pressing against the insulation layer between, is called "natural frequency" (fr) (Simultaneous Vibration Frequency). The value of natural frequency depends on the zone weights of the two layers and the dynamic rigidity ( $\left.\mathrm{s}^{\prime}\right)$ of the insulation layer between and fr can be calculated using the below equation:

$$
\mathrm{fr}=500 \sqrt{ } \mathrm{s}^{6}\left[(1 / \mathrm{M} 1)+\left(1 / \mathrm{M}^{2}\right)\right](\mathrm{Hz})
$$

Where:

$\mathrm{fr}=$ Natural frequency (Sim. Vib. Freq.) $(\mathrm{Hz})$,

$\mathrm{s}^{\prime}=$ Insulation layer dynamic rigidity $\left(\mathrm{kp} / \mathrm{cm}^{3}\right)$

M1 and M2=Zone weights of outer and inner layers $\left(\mathrm{kg} / \mathrm{m}^{2}\right)$ (Table 6).

Dynamic Rigidity ( $s^{\prime}$ ) of the insulation layer in the equation is called the elasticity of the insulation layer placed between the layers and used for sound damping.

$\mathrm{s}^{\prime}=\mathrm{E} / \mathrm{a}\left(\mathrm{kp} / \mathrm{cm}^{3}\right)$

Where:

$\mathrm{E}=$ Dynamic elasticity module $\left(\mathrm{kg} / \mathrm{cm}^{2}\right)$ (Table 6)

$\mathrm{a}=$ Thickness of intermediate layer or space $(\mathrm{cm})$

Table 3. Sound Levels from the Noise Sources (dB) (Young 1988)

\begin{tabular}{|l|l|}
\hline Very light: $20 \mathrm{~dB}$ & Whisper, leaf rustling, background noise in broadcast studios \\
\hline Light: $30 \mathrm{~dB}$ & Speaking with low voice, auditorium environment \\
\hline Light: $40 \mathrm{~dB}$ & Private office, quiet house, quiet environment away from traffic \\
\hline Moderate: $50 \mathrm{~dB}$ & Low-volume radio \\
\hline Moderate: $60 \mathrm{~dB}$ & Speaking with moderate voice, noisy room \\
\hline High: $70 \mathrm{~dB}$ & Medium noisy industry, medium noisy street \\
\hline High: $80 \mathrm{~dB}$ & Noisy office \\
\hline Very high: $90 \mathrm{~dB}$ & Police whistle, truck noise, noisy industry zone \\
\hline Very high: $100 \mathrm{~dB}$ & High street noise \\
\hline Deafening: $110 \mathrm{~dB}$ & Heavy industry, steel riveting \\
\hline Deafening: $120 \mathrm{~dB}$ & Thunder, airplane sound at departure \\
\hline
\end{tabular}


Table 4. Acceptable Background Audible Sound Levels in Areas with Human Activity (Beranek and Ver 1992)

\begin{tabular}{|l|c|}
\hline Area Types & $\begin{array}{c}\text { Approx. Sound } \\
\text { Levels (dB) }\end{array}$ \\
\hline Radio Broadcasting and Recording studios (Using microphone) & 18 \\
\hline Concert hall, Opera houses etc. (For listening to light music) & 28 \\
\hline $\begin{array}{l}\text { Broad auditorium, Drama theater etc. (For very good listening } \\
\text { conditions) }\end{array}$ & 33 \\
\hline $\begin{array}{l}\text { Radio-TV Broadcast and recording studios (Using closed } \\
\text { microphone) }\end{array}$ & 38 \\
\hline $\begin{array}{l}\text { Small Auditoriums and theaters, Musical showrooms (For very } \\
\text { good listening) or Conference halls for 50 people }\end{array}$ & $38-48$ \\
\hline $\begin{array}{l}\text { Bedrooms, sleeping quarters, Hospitals, Apartments, Hotels, } \\
\text { Motels vb. (For resting, sitting and sleeping), Small conference } \\
\text { rooms, Classes, Libraries, Hospital rooms for 2-4 people (For good } \\
\text { resting cond.), Living rooms in houses (Chatting while radio or TV } \\
\text { is on) }\end{array}$ & $43-53$ \\
\hline $\begin{array}{l}\text { Broad offices, Receptions, Retail stores, Stores, cafes, Dining } \\
\text { houses, etc. (For barely good resting conditions) }\end{array}$ & $48-58$ \\
\hline $\begin{array}{l}\text { Lobbies, Special working laboratories, Technical drawing and } \\
\text { Engineering } \\
\text { drawing rooms, General secretarial rooms (For full rest conditions) }\end{array}$ & $53-63$ \\
\hline $\begin{array}{l}\text { Light food places, Industrial plant control rooms, Computer } \\
\text { hardware rooms, Kitchens, Laundry (For barely good full resting } \\
\text { conditions) }\end{array}$ & $63-78$ \\
\hline $\begin{array}{l}\text { Shops, Garages etc. (For acceptable communication and phone } \\
\text { communication centers) For locations with levels not } \\
\text { recommended for any office and communication centers }\end{array}$ & $58-68$ \\
\hline $\begin{array}{l}\text { For noisy working places or phone communication centers where } \\
\text { verbal communication is possible, where sound is unwanted but it } \\
\text { doesn't distract hearing }\end{array}$ & \\
\hline
\end{tabular}

The "Reinforced Concrete Prefabricated" facade elements used on the facades of industrial buildings, when they are multi-layered in cross-sectional dimension, the reinforced concrete outer and inner layers are connected to each other by tie bars. Therefore, while the section is being dimensioned, the sound insulation level calculation (R0) must be calculated taking into account sound bridges. The following equation can be used in calculations:

$\mathrm{R}_{0}=10\left[\log \_1\right] \mathrm{dB}$

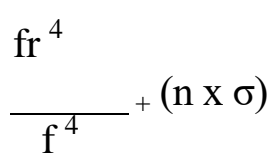

Where:

$\mathrm{F}=$ Frequency, $(\mathrm{Hz})$

$\mathrm{fr}=$ Natural frequency of the facade element (Sim. Vibr. Freq.) $(\mathrm{Hz})$

$\mathrm{n}=\mathrm{Quantity}$ of sound bridges

$\sigma=$ Sound reflection degree 
The sound reflection degree in the spot-sectioned sound bridges of the reinforced concrete prefabricated facade element can be calculated using the below formula:

$$
\sigma=\frac{8}{\pi^{2}} \times \frac{c^{2}}{f_{g} \cdot S}
$$

Where:

$\mathrm{c}=$ Sound spread speed in iron $(\mathrm{m} / \mathrm{s}),($ Table 5) (Özer 1979)

$\mathrm{S}=$ Cross section area of sound bridge $\left(\mathrm{cm}^{2}\right)$

$\mathrm{fg}=$ Limit frequency of facade element's outer layer $(\mathrm{Hz})$

$$
\mathrm{f}_{\mathrm{g}}=\frac{\mathrm{c}^{2}}{2 \mathrm{c}_{\mathrm{L}} \cdot \mathrm{d}}
$$

$\mathrm{d}=$ The thickness of the outer layer of the facade element (m),

$\mathrm{c}=$ Sound spread speed in iron $(\mathrm{m} / \mathrm{s}),($ Table 5$)$

$c_{L}=$ Vertical waves' spread speed in the plate $(\mathrm{m} / \mathrm{s})$, (Table 6$)$

\begin{tabular}{|c|c|c|}
\hline Material & Sound Spr. Speed c(m/s) & Unit Weight $\left(\mathrm{kg} / \mathrm{m}^{3}\right)$ \\
\hline Concrete & 4000 & 2000 \\
\hline Aluminum & 5200 & 270 \\
\hline Lead & 1300 & 11340 \\
\hline Steel & $1000-4000$ & 7800 \\
\hline Cork & 500 & 200 \\
\hline Air $\left(\sim 15^{0}\right)$ & $330-350$ & 1.2 \\
\hline Water & 1453 & 1000 \\
\hline
\end{tabular}

Table 5. Sound Spread Speed and Unit Weights in Some Materials

In the "Reinforced Concrete Prefabricated" industrial constructions, it is also necessary to take into consideration the door or window clearance inside the element in order to be able to calculate the sound insulation level using the factors affecting the cross-sectional dimension of the facade member. Because of the sound insulation in the element section, the improvement provided within the industry structure should not be adversely affected by the door or window opening. In this respect, the sound insulation level of the door or window (R1) must also be included in the calculation. If the gaps such as doors and windows in the facade element are lower than the sound damping (insulation) capability of the facade element, the structure will be adversely affected. A reinforced concrete prefabricated facade element's sound insulation ( $\mathrm{Rkp})$ with a door or window in it can be calculated using below formula 12:

$$
\mathrm{R}_{\mathrm{kp}}=\mathrm{R}-10 \log \left[1+\frac{\mathrm{F} 1}{\mathrm{~F} 0} \mathrm{x} \frac{\mathrm{R}-\mathrm{R} 1}{10}\left(\begin{array}{c}
10-1) \\
(\mathrm{dB})
\end{array}\right.\right.
$$

Where:

$\mathrm{F} 1=$ Surface area of door or window $\left(\mathrm{m}^{2}\right)$, 
$\mathrm{F} 0=$ Wall area including door or window $\left(\mathrm{m}^{2}\right)$,

$\mathrm{R}=$ The B.A. Prefabricated facade element's sound damping (insulation) rate $(\mathrm{dB})$, $\mathrm{R} 1=$ Sound damping (insulation) of door or window (dB) (Table 7)

Table 6. Constant Value of Some Building Materials (Özer 1979)

\begin{tabular}{|l|c|c|c|}
\hline Material & $\begin{array}{c}\text { Bulk Density } \\
\left(\mathbf{g} / \mathbf{c m}^{\mathbf{3}}\right)\end{array}$ & $\begin{array}{c}\text { Elasticity Module } \\
\left(\mathbf{E}=\mathbf{N} / \mathbf{m}^{\mathbf{2}}\right)\end{array}$ & $\begin{array}{c}\text { Vertical waves' } \\
\text { Spread speed in plate }\end{array}$ \\
\hline High-dens. concrete & $2.0 \ldots .2 .4$ & $(25 \ldots 35) \cdot 10^{5}$ & $3.4 .10^{3}$ \\
\hline Light concrete & $0.6 \ldots .1,3$ & $(2 \ldots \ldots .4) \cdot 10^{5}$ & $1.7 .10^{3}$ \\
\hline Amiant Cement & 2.0 & $28.10^{5}$ & $3.7 .10^{3}$ \\
\hline Plaster & 1.2 & $7.10^{5}$ & $2.4 .10^{3}$ \\
\hline Brick & $(1.8 \ldots .2 .0)$ & $16.10^{5}$ & $(2.5 \ldots .3) .10^{3}$ \\
\hline Lime Stuff & 1.7 & $44.10^{5}$ & $1.6 .10^{3}$ \\
\hline Glass & 2.5 & $60.10^{5}$ & $4.9 .10^{3}$ \\
\hline Flake boards & $0.6 \ldots . .7$ & $4,6.10^{5}$ & $2.7 .10^{3}$ \\
\hline Plexiglass & 1.2 & $5.6 .10^{5}$ & $2.2 .10^{3}$ \\
\hline Glass Foam & $0.13 \ldots .1 .6$ & $(1.3 \ldots 1.6) .10^{5}$ & $3.1 .10^{3}$ \\
\hline Aluminum & 2.7 & $72.10^{5}$ & $5.2 .10^{3}$ \\
\hline Lead & 11.3 & $17.10^{5}$ & $1.3 .10^{3}$ \\
\hline Steel & 7.8 & $210.10^{5}$ & $5.1 .10^{3}$ \\
\hline
\end{tabular}

Table 7. Sound Damping Rates of Windows (R) (Beranek and Ver 1992)

\begin{tabular}{|l|c|c|}
\hline Window Type & Avg. Sound Damping & Rate ( R ) \\
\hline & With elastic webbing & Without elastic webbing \\
\hline Simple Window & $\sim 20 \mathrm{~dB}$ & $\leq 25 \mathrm{~dB}$ \\
\hline Double-Glazing & $\sim 25 \mathrm{~dB}$ & $\leq 30 \mathrm{~dB}$ \\
\hline Double Casement & $\sim 20 \mathrm{~dB}$ & $\leq 40 \mathrm{~dB}$ \\
\hline
\end{tabular}

In double glass (layer) door and window formation, the $\mathrm{g} x \mathrm{a}>100$ formula should be watched.

Where:

$\mathrm{g}=$ Layer area weight $\left(\mathrm{kg} / \mathrm{m}^{2}\right)$ (Table 4)

$\mathrm{a}=$ Distance between layers.

Example Solution with "MT2 Prefabrike" Program

While the dimensional analysis of the "reinforced concrete prefabricated" facade elements used in the industrial buildings' facades is done, another thing to be considered in determining the section size is the sound insulation performance of the element. When the sound performance of the element cross-section is measured, some data must also be entered into the program. These are:

Outdoor Air Sound (dB): In order to be able to measure which facade element is able to attenuate a high level sound, the outside air sound must be entered as data in the "Outside Air Sound (dB)" window of the program. These values are shown in Table 4. 
Frequency (fr): By measuring the frequency of the environment, the obtained value must be added to the window of the "frequency (fr)" in the program.

Working Hours of Industry Structure: It is necessary to decide which of the activities in the industry structure will be carried out in the daytime or nighttime environment and to check the options indicated in the program window. Because the program will calculate the sound level for these two separate media separately and will thus analyze them separately. The element cross-section will be sized in such a way as to produce a suitable working environment inside against this outside air noise.

Sound attenuation measure (Rpk) calculations of the facade element will be done as such:

1. Night (22.00-06.00) Rpk $<50 \mathrm{~dB}$

2. Day (06.00-22.00) Rpk $<60 \mathrm{~dB}$

Only those sections that meet these conditions will give the appropriate analysis report.

Door/Window: When the element cross-section is determined, there are a number of factors that affect the outcome of the above analyses and should not be overlooked in the program. These are the Door/Window gaps in the element. The program offers options for these too. If there is a door/window opening in the front element, the combination criteria in terms of the dimensions of the opening and the sound technique of the doors and windows are also offered to the user as an option.

The program makes all insulation calculations according to these preferences. The facade element section can be verified until the sound insulation reaches the appropriate values and the program can continue to feed back until proper insulation is obtained.

By entering the above data, the program is then ready to perform sound insulation analysis. If the data is changed for sound insulation analysis, the result will change. If the outside air volume is high $(140 \mathrm{~dB})$ as in the above example, the operation will start with the "Analysis" command button and the dimensions of this element will be "Not suitable" in terms of the sound technique (Rpk) (Figure $15)$.

Analysis Results

This section is used to evaluate all of the previous study stages (Temperature, Sizing, Static). It will display the precautions to be taken according to the results obtained. If, as in the above example, the sound insulation performance of the facade element is not sufficient and the message "Not suitable" is received, then in the Analysis Results section, the necessary precautions will be taken to take precautions. Some precautions are:

- The thickness of sound insulation material can be increased.

- The door/window opening of the façade member may be reduced or removed if possible. 
- Door/window joining technique options can be reviewed.

- Frequency can be lowered.

- The outdoor noise level can be reduced.

If all of this is inadequate, the process should be re-checked by adding a highsound-insulation material to the section of the "Reinforced Concrete Prefabricated" facade element. For this, the "Heat", "Size" and "Static" analyzes of the element are repeated until the sound analysis.

\section{Figure 15. The Program's “Not Suitable” Analysis Window}

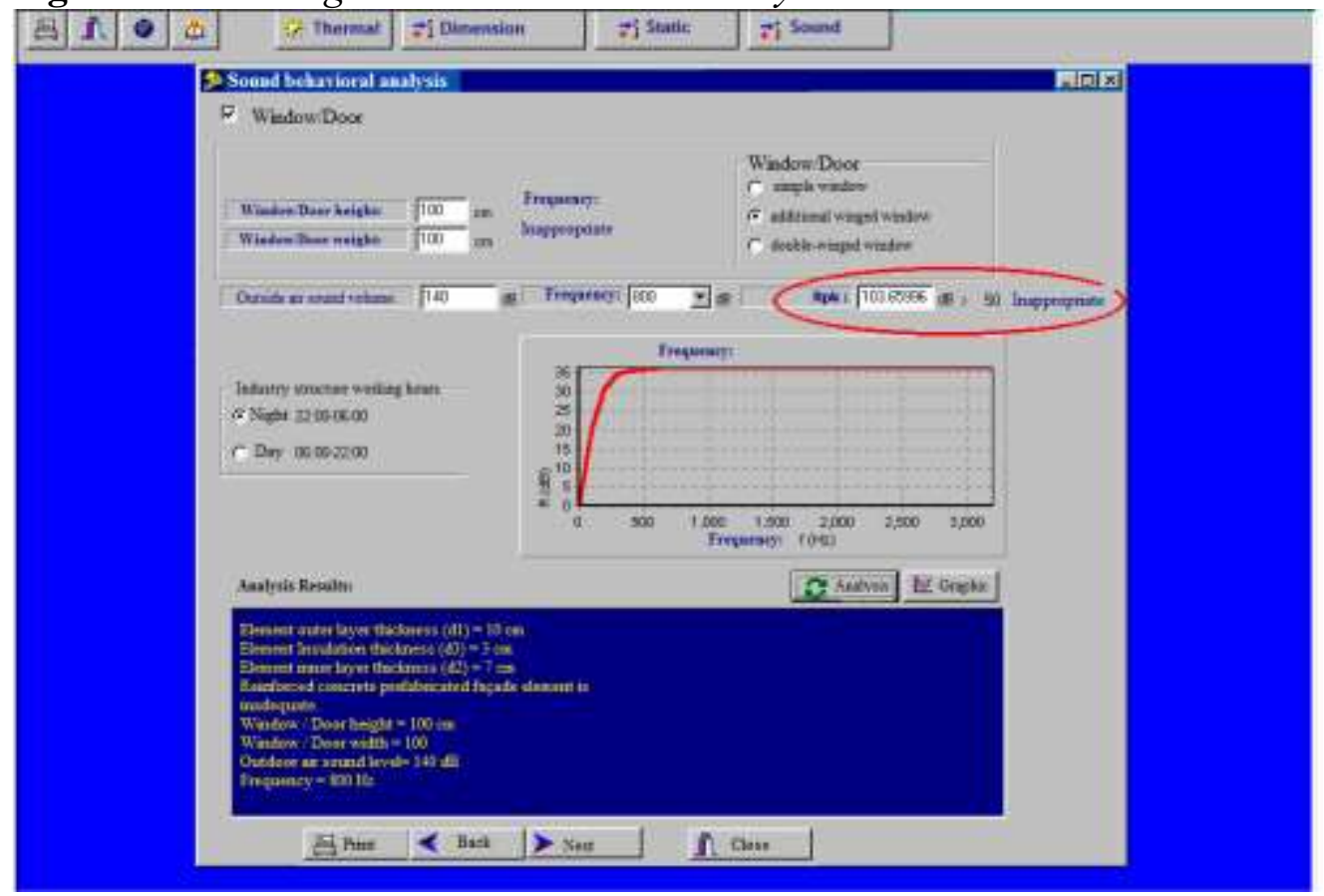

Sound Damping Rate/Frequency Graphic

After the sound insulation performance of the front element is made with the "Analysis" command button, the Frequency ( $\mathrm{f}=\mathrm{Hz}$ ) Graph will be drawn in the program Sound Damping Rate $(\mathrm{R}=\mathrm{dB})$ based on the last found values of the element. It will suffice to press the "Graphic" command button for this. When the "graphic" command button is pressed the program will prepare the graphic which indicates the relation between "Sound damping rate $\mathrm{R}(\mathrm{dB})$ and Frequency $\mathrm{f}(\mathrm{Hz})$ " (Figure 16). This graphic will come to the computer screen as a separate window and will give the numerical values of the breakpoints. In other words, "Sound Damping Rate" $(\mathrm{R}=\mathrm{dB})$ can be tracked according to "Frequency (fr)" changes. The Graphic's "Zoom" function can be used for detailed views. This procedure will be completed with analyses and the user will be able to select "Back", "End", "Close" or "Print" command buttons to finish the process. 
Figure 16. The Program's "Graphic” Window for Sound Insulation

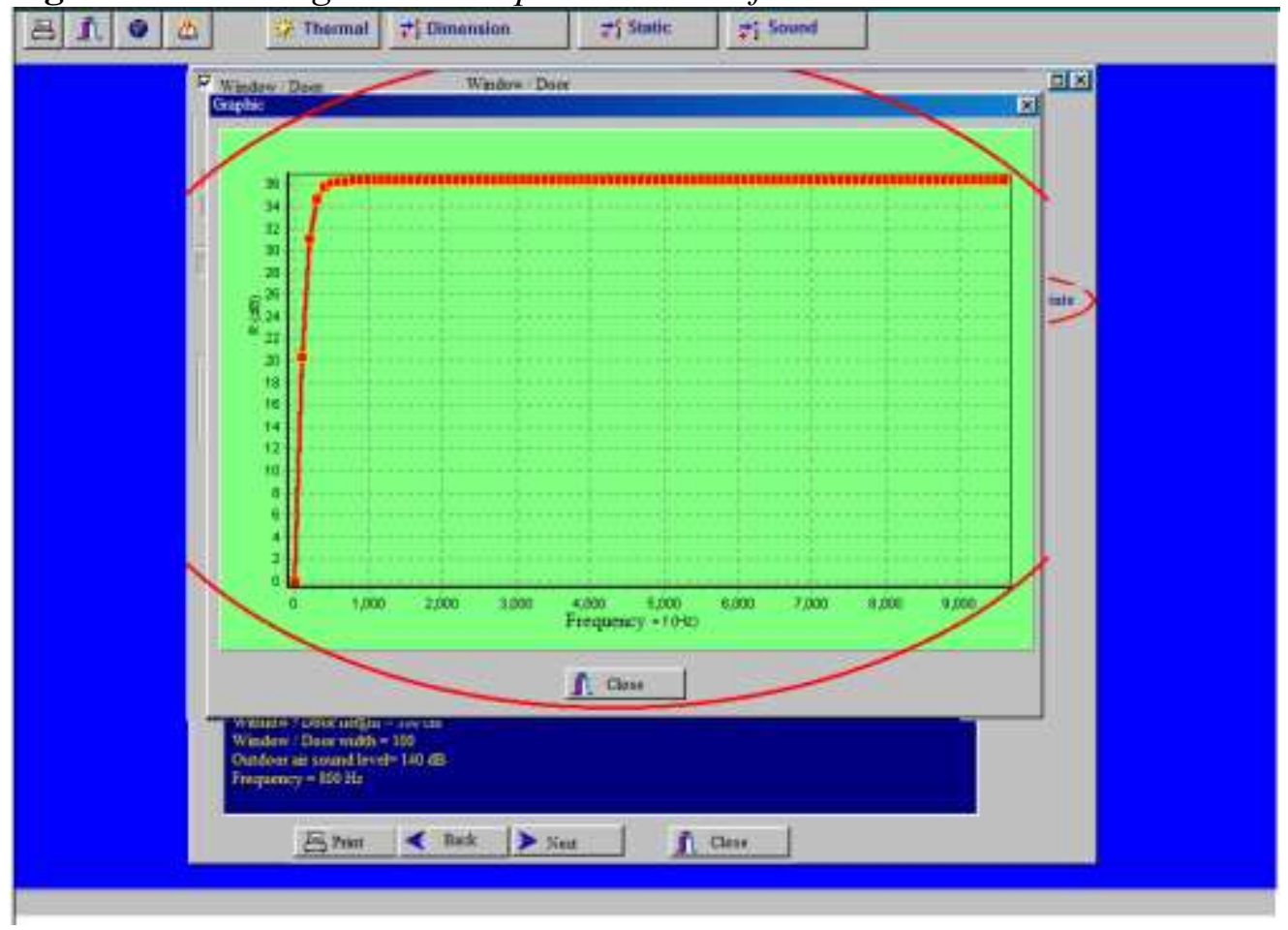

\section{Conclusion}

This model software is prepared for multi-layered and non-carrier reinforced concrete. Prefabricated facade elements used in facades of Industrial Structures. For this software, firstly the dimensional performance and behaviors expected from the front elements were defined and the factors affecting them were determined. Later, calculations on the factors affecting dimensions of facade elements:

- Thermal insulation

- Coordination dimensions

- Carrying properties (static)

- Sound insulation feature can be made and optimum results can be obtained by evaluating these calculations. The results can be displayed in the "MT2 Prefabrike" analysis program in a virtual world window.

This model software will play an important role in giving product decisions before production of facade element. These are:

1. The facade element will have the required "Thermal Insulation" fittings for application everywhere in Turkey. 
2. According to the design form of the element on the facade, "Coordination Dimension" (A) will be calculated and it will facilitate the necessary infrastructure preparations for the production of the element.

3. With optimization of the "Element's Carrying Features" (static) risks of breaks and cracks can be eliminated.

4. Industrial structures will have "Sound Insulation" fittings to continue to function well in noisy environments.

This "MT2 Prefabricated" dimensional analysis program, developed for "Reinforced Concrete. Prefabricated Facade Elements", is also a "Model" in terms of reducing diversity of dimensional behaviors expected from "Reinforced Concrete Prefabricated" structural members and facilitating "Standardization" approaches.

With this software, it is aimed to bring a correct view to the problem of the misunderstood standard concept of prefabricated building elements and is exemplified on a model.

\section{References}

Azhar S (2011) Building Information Modeling (BIM): trends, benefits, risks, and challenges for the AEC industry. American Society of Civil Engineers 11(3).

Azhar S, Nadeem A, Mok JYN, Leung BHY (2008) Building information modeling (BIM): a new paradigm for visual interactive modeling and simulation for construction projects. In Proceedings of the First International Conference on Construction in Developing Countries, 435-446. Karachi, Pakistan.

Bakır E (1990) Design principles guide of prefabricated reinforced concrete buildings. Ankara: Prefabricated Association.

Beranek LL, Ver, IL (1992) Noise and vibration control engineering. In Principle and Aplications. USA.

Cansun O (1989) Curtain wall. Lecture Notes. İstanbul: Department of Building, İ.T.Ü. Faculty of Architecture.

Christiane MH, Davide L, Isaac G (2018) Parametric design of sculptural fibre reinforced concrete facade components: learning, adapting and prototyping. In Proceedings of the 23rd International Conference of the Association for Computer-Aided Architectural Design Research in Asia (CAADRIA) 2018, volume 2, 319-328.

Chudley R (1994) Construction technology. Second Edition. Pearson India.

Eastman C, Teicholz P, Sacks R, Liston K (2008) BIM handbook: a guide to building information modeling for owners, managers, designers, engineers and contractors. New York: Wiley.

Eriç M (1994) Building physics and materials. Istanbul: Literature Publications 2.

Escrig F, Brebbia CA (1996) Mobile rapidly assembled structure-II. Southampton: Bookcraft Limited.

International Standardization Organization - ISO (1990) Accoustics - Determination of occupational noise exposure and estimation of noise-induced hearing impairment. ISO 1999.2. Geneva, Switzerland.

Lantim D (1998) Delphi 3. Computer Software. Paris: Eyrolles.

Montali J, Overend M, Pelken PM, Sauchelli M (2017) Knowledge-based engineering applications for supporting the design of precast concrete facade panels. In DS 87-6 
Proceedings of the 21st International Conference on Engineering Design (ICED 17), volume 6, 131-139. Vancouver, Canada.

Özer M (1979) Building acoustics and sound insulation. Istanbul: Arpaz Publishing.

Şener H (1990) Open Systems in Industrialized Building. Architecture Print Workshop. Istanbul: İ.T.Ü. Faculty of Architecture.

TSE 825 (1999) Thermal insulation requirements for buildings. Ankara: T.C. Bayındırlık ve İskan Bakanlığı.

Wang-Dong Y, Qiang C, Ni L (2011) A framework-based model of software construction. In IEEE 2nd International Conference on Software Engineering and Service Science, DOI=10.1109/ICSESS.2011.5982310.

Young RW (1988) Optimum levels for reporting community noise. Washington, USA: Private Communication. 
